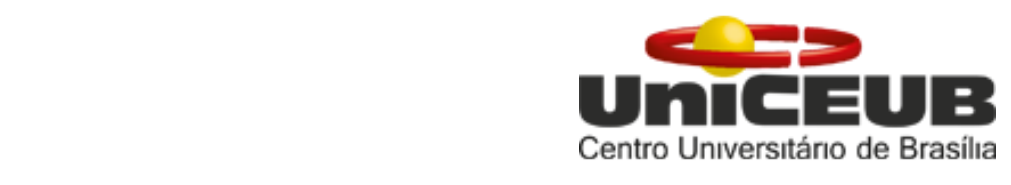

CENTRO UNIVERSITÁRIO DE BRASÍLIA - UnICEUB

FACULDADE DE CIÊNCIAS DA EDUCAÇÃO E DA SAÚDE - FACES PROGRAMA DE INICIAÇÃO CIENTÍFICA - PIC

\author{
BARBARA CRISTINA DE CARVALHO OLIVEIRA \\ JÉSSICA DE SOUSA SILVA
}

\title{
ESTUDO DE RECRUTAMENTO DE FAMÍLIAS DE DIPTERA DE INTERESSE FORENSE
}




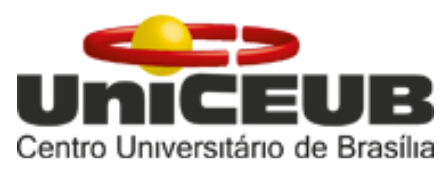

\section{BARBARA CRISTINA DE CARVALHO OLIVEIRA JÉSSICA DE SOUSA SILVA}

\section{ESTUDO DE RECRUTAMENTO DE FAMÍLIAS DE DIPTERA DE INTERESSE FORENSE}

Relatório final de pesquisa de Iniciação Científica apresentado à Assessoria de Pós-Graduação e Pesquisa pela Faculdade de Ciências da Educação e da Saúde - FACES

Orientação: Prof. Dr. Paulo Roberto Martins Queiroz

\section{BRASÍLIA-DF}


RESUMO

\title{
ESTUDO DE RECRUTAMENTO DE FAMÍLIAS DE DIPTERA DE INTERESSE FORENSE
}

\author{
Jéssica De Sousa Silva - UniCEUB, PIBIC-CNPq, aluno bolsista \\ Jessicadesousa.silva17@gmail.com
Barbara Cristina De Carvalho Oliveira - UniCEUB, PIBIC-CNPq, aluno voluntário Barbaracristina93@gmail.com

Paulo Roberto Martins Queiroz - UniCEUB, professor orientador Paulo.silva@uniceub.br

A Entomologia Forense é uma das áreas que consegue informações relevantes a partir da análise do comportamento, alimentação, reprodução e características morfológicas de insetos necrófagos que estão presentes em uma investigação criminal. Ela também auxilia na identificação do IPM (intervalo pós-morte) contribuindo, diretamente, na medicina legal. Esse intervalo pode ser encontrado por meio da rigidez cadavérica, resfriamento do corpo, livores cadavéricos, fases de decomposição e da fauna cadavérica. O estudo das principais famílias de insetos de interesse forense vem crescendo no intuito de auxiliar na determinação do tempo de morte. Os insetos de maior relevância pertencem às ordens Díptera e Coleóptera. As famílias de Díptera mais importantes são Calliphoridae, Sarcophagidae e Muscidae, sendo que estes insetos atuam de forma fundamental na decomposição da matéria orgânica. Este trabalho teve como objetivo a análise da distribuição da frequência acumulada desses insetos de interesse forense em duas localidades diferentes situadas no Distrito Federal. Foram utilizadas três armadilhas simples confeccionadas com material reciclável contendo em torno de $100 \mathrm{~g}$ de matéria orgânica deixada em decomposição. As coletas dos adultos foram feitas diariamente durante um período de 7 dias. Foram avaliados parâmetros, tais como, localização, estação do ano, tipo de carne usada, horário de coleta, temperatura e umidade. As análises desses parâmetros indicam que as famílias de insetos analisadas nesse estudo têm o seu comportamento influenciado pelas variações ambientais. Foram coletados ao todo 4.212 insetos, sendo 1.562 pertencentes à família Calliphoridae, 172 a Sarcophagidae, 694 a Muscidae e 1.784 a outros insetos. Foram feitas análises de frequência acumulada e de distribuição sendo possível estabelecer um padrão de recrutamento dos adultos em relação à matéria orgânica em decomposição. Esse padrão foi obtido por modelagem de curvas indicando que Calliphoridae e Muscidae possuem o mesmo padrão de recrutamento enquanto Sarcophagidae possui um padrão típico.

Palavras-chave: Calliphoridae; Muscidae; Sarcophagidae. 
SUMÁRIO

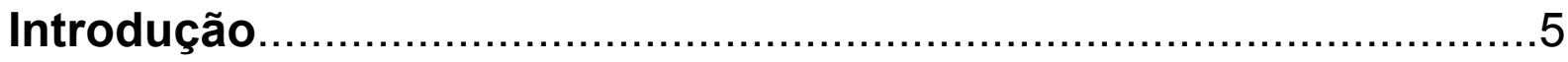

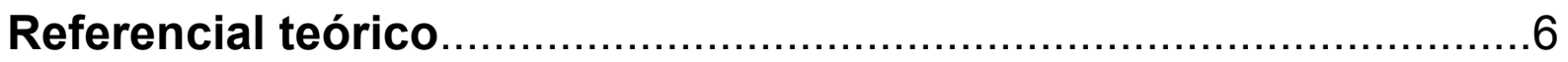

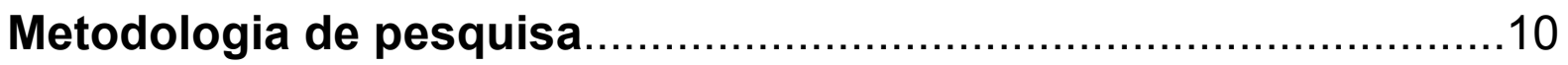

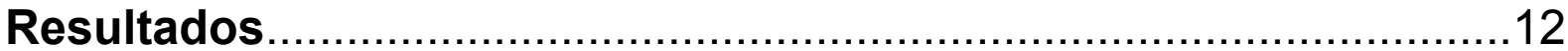

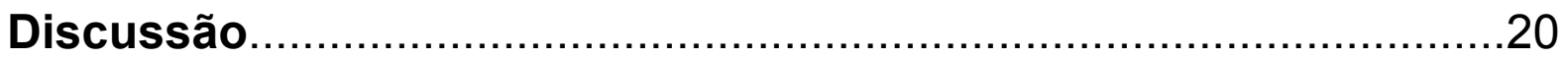

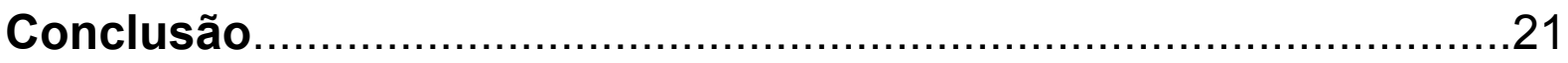

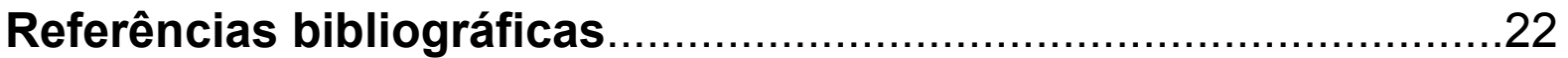




\section{INTRODUÇÃO}

A Entomologia Forense é uma ciência que aplica os estudos dos insetos nos procedimentos médico-legais (OLIVEIRA-COSTA, 2008). Viabiliza na identificação da data da morte, se o corpo foi manipulado ou movido para outro local, investigações sobre danos imobiliários, tráficos, maus tratos e vítimas de mortes violentas. Ela pode esclarecer, principalmente, o tempo entre a morte e a data que o cadáver foi encontrado, o lugar onde ocorreu o crime e a causa da morte (SANTANA; BOAS, 2012).

Ela está dividida em três principais áreas: a Entomologia Urbana (que estuda as interações entre os insetos e o ambiente urbano); Entomologia de produtos estocados (dedica-se a estudar as relações entre insetos e a infestação de produtos estocados); e a Entomologia Médico-Legal (estuda os insetos que são úteis nas investigações criminais, usualmente em crimes violentos como assassinatos, estupros e suicídios; envolve insetos necrófagos que geralmente vivem em contato com restos humanos ou animais em decomposição), sendo as duas primeiras intimamente relacionadas à saúde pública (GOMES, 2010).

O primeiro caso documentado de entomologia forense está relatado em um manual de medicina legal chinês do século XIII, no qual é descrito um caso de homicídio em que um lavrador apareceu degolado por um instrumento de ação corto-contundente. Para a resolução do caso, todos os lavradores da região foram obrigados a depositar suas armas de trabalho no chão, ao ar livre. As moscas pousaram em apenas uma delas, atraídas pelos odores e restos de sangue que ainda permaneciam aderidos à lâmina, e, assim, concluiu-se que aquela era a arma usada para cometer o homicídio. Contudo, só em 1855, se teve o primeiro caso que incluiu a estimativa do intervalo post mortem (IPM) pelo médico francês Bergeret através da Entomologia Forense (CAINÉ, 2010)

O intervalo pós-morte (IPM) é dado pelo tempo entre a ocorrência da morte e quando o corpo foi encontrado. Nos casos que são suspeitos, o IPM é de extrema importância no momento em que é realizando a reconstrução dos eventos e das circunstancias da morte, na veracidade das informações dadas pelas testemunhas e na ligação do suspeito com a cena do crime ou a vítima. A estimativa desse intervalo dado por métodos entomológicos é baseada em padrões estabelecidos pela 
sucessão dos insetos e o estágio de desenvolvimento do mesmo, que foram coletados no cadáver em decomposição. Portanto, ter o conhecimento sobre os fatores que podem gerar uma interferência na decomposição e colonização do cadáver se tornou de grande importância para a identificação do IPM de forma precisa (PINHEIRO et al., 2012).

Com o equilíbrio da temperatura do corpo e do meio ambiente e, inicio de putrefação, acaba inviabilizando a utilização da estimativa tradicional viável do IPM. Sendo que, as técnicas médicas só irão ser precisas durante os primeiros dois ou três dias pós-morte. No entanto, ao utilizar cálculos da idade do inseto imaturos que se alimentam do cadáver e análise de espécies necrófagas presente irá proporcionar uma estimativa do IPM em um período de dias e meses (MARTINS, 2013)

Peritos criminais e legistas passaram a usar a Entomologia para auxiliar no aprimoramento de seus trabalhos levando assim a divisão dela em três categorias, a urbana, que consiste em ações civis associadas à uma presença de insetos em imóveis, há também a de produtos estocados, a qual aborda sobre a contaminação de produtos comerciais estocados e, por fim, a do médico-legal que está relacionada à área criminal (BRASIL, 2006).

No Brasil essa ciência veio se desenvolvendo de forma contínua tendo a realização de estudos sobre os insetos das ordens Diptera e Coleoptera. Logo, o conhecimento taxonômico desses insetos se tornou indispensável na Entomologia, pois esses dados serão associados ao intervalo pós-morte que irá depender de informações biológicas e ecológicas, principalmente quando se tratar sobre o desenvolvimento pós-embrionário das espécies das famílias Calliphoridae, Muscidae, Sarcophagidae e Stratiomydae (LUZ et al., 2008).

A presente pesquisa objetivou a análise da distribuição da frequência acumulada desses insetos de interesse forense em duas localidades diferentes situadas no Distrito Federal.

\section{REFERENCIAL TEÓRICO}

Utilizando-se os conhecimentos já descritos à respeito da entomofauna presente no corpo após a morte e no local onde o mesmo foi encontrado, é possível obter informações quanto à: 
- Identidade do morto: Através da análise do DNA, obtido de sangue e outros tecidos presentes no intestino do inseto (ROMANA et al., 2012);

- Causa da morte: a velocidade de decomposição e a sucessão de insetos no cadáver são afetadas por diferentes formas de morte (afogamento, envenenamento, carbonização, estupros, etc) (ROMANA et al., 2012);

- Movimentação do corpo: Há certa diferença entre a atividade de insetos de diversos ambientes, sendo que as espécies envolvidas podem variar de região para região (ROMANA et al., 2012);

- Uso de drogas e toxinas: Estas substâncias provocam efeitos no desenvolvimento dos insetos, desde o desenvolvimento larval até o tempo de pupariação (GUPTA; SETIA, 2004);

- Determinação do intervalo pós-morte (IPM): Dados dos hábitos e biologia das espécies associadas às carcaças podem auxiliar na determinação do intervalo de tempo mínimo e máximo, entre a morte e a data em que o corpo foi encontrado (ROMANA et al., 2012).

As carcaças são colonizadas por uma enorme quantidade de insetos e a atividade dessas espécies acelera a putrefação cadavérica e cada estágio do corpo tem fases próprias que atraem determinados grupos de insetos, porém nem todos despertam o interesse forense. Inegavelmente, a entomologia forense só pode ser aplicada em áreas em que a composição e a biologia da fauna de insetos (em diferentes fases de carniça em decomposição) já são conhecidos (PINTO et al., 2011).

Os insetos mais importantes pertencem às ordens Diptera - que poderão ser encontradas em os habitats - (famílias Calliphoridae (As espécies dessa família, vulgo mocas azuis, atuam de forma fundamental na decomposição de material orgânico, onde na fase adulta irão ser atraídos por matéria em putrefação), Sarcophagidae (são encontrados com mais probabilidade, nos interiores ou em condições adversas ao voo a outros insetos. Os adultos dessa família são atraídos por substâncias adocicadas, apesar de poderem ser encontrados nos primeiros e últimos estágios de decomposição. Sendo que, a sua larva será atraída para materiais em decomposição) e Muscidae - Figura 1) e Coleoptera (famílias Silphidae, Dermestidae, Cleridae, Histeridae e Scarabaeidae) (RAMOS, 2010). 
No entanto, existe uma grande influência de fatores externos como temperatura, luminosidade e vegetação que podem distorcer as informações sobre a sucessão das espécies colonizadoras de cadáveres (ROMANA et al., 2012).

Figura 1: Mosca Doméstica (Muscidae)

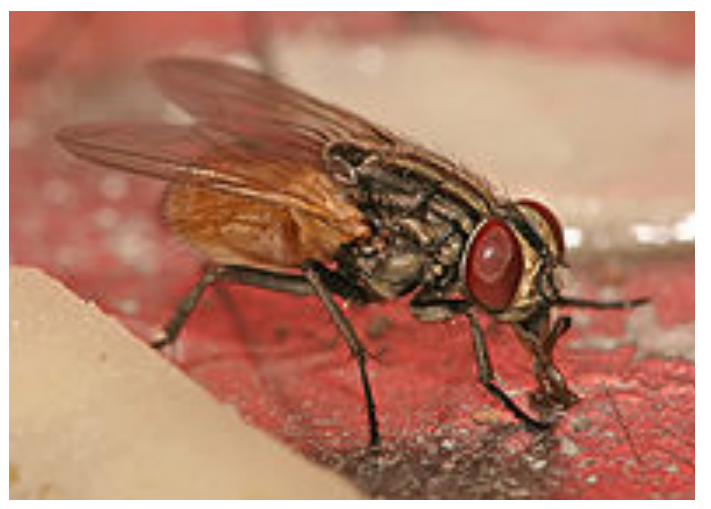

Fonte: Biosurvey, 2004.

Um grande problema enfrentado pelos entomologistas é a identificação precisa das larvas coletadas em cadáveres, quando muitas vezes somente espécimes mortos e mal preservados são submetidos à identificação. Conhecer os insetos próprios de cada ambiente (floresta, urbano, local fechado ou aberto, iluminado ou escuro), bem como a temperatura ótima para o desenvolvimento das espécies e a relação entre a atividade (comportamento) e estações do ano, promovem subsídios para o esclarecimento de questões que envolvem remoção do corpo, negligencia antes da morte, causa da morte, quando ocorreu e como ocorreu o crime (ROMANA et al., 2012).

Por isso que as pesquisas relacionadas a distribuição taxonômica de cada região é fundamental para a estimativa do IPM. A identificação das principais famílias e a biologia dos insetos necrófagos podem contribuir significativamente em procedimentos legais e ser uma peça de alto valor criminalístico, posteriormente também contribuir nos estudos desta área (ROMANA et al., 2012).

Essa estimativa de IPM é realizada por meio de dois métodos: um deles é na utilização de insetos dípteros pertencentes ás famílias Calliphoridae (Figura 2) e Sarcophagidae (Figura 3), mais frequentemente durante 0 processo de decomposição cadavérica, de informações relacionadas a uma estimativa da idade dos estágios imaturos que usufruem do cadáver como fonte de alimento. Após o 
depositamento dos ovos desses dípteros no cadáver, alguns minutos após a morte ter ocorrido, irá permitir com a idade dos ovos, larvas ou das pupas mais antigos, uma estimativa de um IPM mínimo. Já o outro método se trata em uma secessão de forma progressiva de artrópodes identificados no cadáver e, em cada fase de decomposição do mesmo, a atração de determinadas espécies. Ao ter uma realização de uma análise dessa sucessão de artrópodes poderá gerar informações sobre o tempo decorrido após a morte, dando estimativas de intervalos mínimos e máximos de IPM (RAMOS, 2010).

Figura 2: Inseto da família Calliphoridae

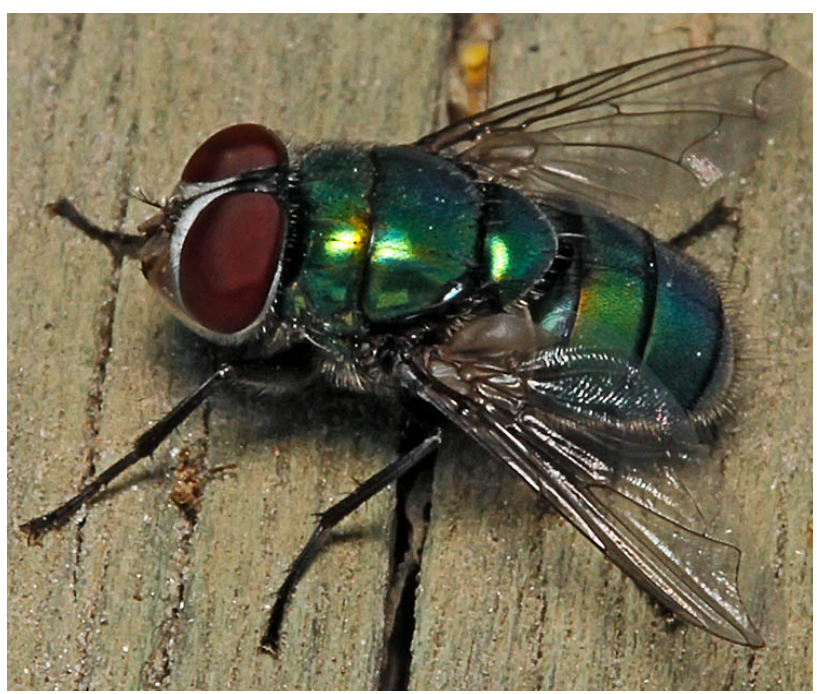

Fonte: Diptera.info, 2011.
Figura 3: Inseto da família Sarcophagidae

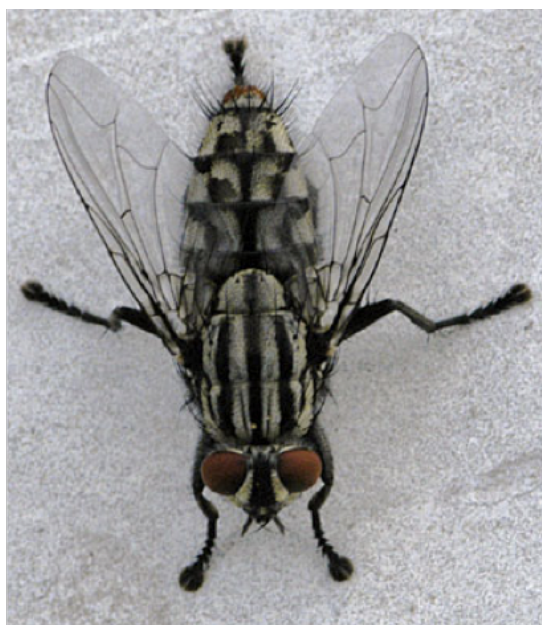

Fonte: Biosurvey, 2004.

O primeiro método citado irá precisar de uma espécie de prova entomológica para poder ser, de fato, um passo essencial na análise forense. Já o segundo, o de análise do conteúdo gástrico larvar, com a utilização de larvas que foram desenvolvidas no cadáver ou em um local próximo a ele (RAMOS, 2010).

O mais comum, em métodos moleculares, na entomologia forense seria a identificação genética da espécie, incluindo a identificação do cadáver com base ao conteúdo gástrico larvar ou a caracterização genética de um grupo especifico dos insetos de interesse forense (RAMOS, 2010).

Ao adquirir o DNA humano, através dos insetos, poderá ser usada de forma ampla, como, por exemplo, na identificação de um suspeito que realizou uma agressão sexual, ou a realização de uma genotipagem de indivíduos a partir de mosquitos (RAMOS, 2010). 


\section{METODOLOGIA DE PESQUISA}

Para a realização da coleta dos adultos de díptera foi necessário a utilização de três armadilhas confeccionadas a partir de garrafas PET e constituídas por duas partes (Figuras 4 e 5), uma inferior que possuía aberturas para a entrada dos insetos e outra superior onde eles ficavam contidos, adaptadas com base a metodologia de Guimarães e Guimarães (2003). Elas ficaram penduradas a $1,5 \mathrm{~m}$ de altura a partir do solo e com uma distância entre elas de $2 \mathrm{~m}$, em localidades diferentes do Distrito Federal.

Para atrair as moscas para a armadilha, utilizou-se $100 \mathrm{~g}$ de carne bovina moída, que foi mantida durante o período de 7 dias de realização de cada experimento (em algumas coletas houve variação de um dia a mais ou a menos nesse período de coleta). Esse material orgânico ficou exposto durante todo o período do experimento no centro de cada armadilha sem qualquer interferência, garantindo a sua passagem nas várias etapas de decomposição como a mudança de cor, exalação de odores e inchaço.

As coletas dos insetos foram feitas em intervalos de $24 \mathrm{~h}$, sendo retirados todos os insetos presentes na armadilha. A retirada dos insetos ocorreu pela abertura superior, onde foram posteriormente mantidos em um saco plástico com fecho hermético, o qual era refrigerado a $-20{ }^{\circ} \mathrm{C}$ e, após quinze minutos eram levados para a retirada dos insetos, colocando-os em potes plásticos, contendo álcool $70 \%$, devidamente identificados e individualizados para cada armadilha. Também foi registrado os dados de temperatura e umidade da hora da coleta dos insetos, de acordo com o Instituto Nacional de Meteorologia de Brasília (INMET), para a análise dos dados finais.

Ao final do período de cada coleta, as amostras que estavam armazenadas no álcool 70\% foram levadas para o Laboratório Multidisciplinar de Ciências (Labocien) do UniCEUB, onde foram separadas, classificadas e contadas em função das famílias e espécies de díptera com a ajuda de uma lupa estereoscópica. Os indivíduos foram separados por dia de coleta, respeitando-se as amostras de cada armadilha e classificados ao nível de família. Todos os dados foram anotados em planilhas especificas para cada armadilha e data que se obteve àquela amostra.

As coletas foram realizadas em duas cidades satélites de Brasília, sendo definido como local 1: Santa Maria e, local 2: Sobradinho. A área é perto de 
ambientes domiciliares, porém apresenta mínima ação humana. As coordenadas exatas do local onde foram dispostas as armadilhas também foram aferidas sendo: local 1: $16^{\circ} 1^{\prime} 41^{\prime \prime} \mathrm{S}-48^{\circ} 1^{\prime} 29^{\prime \prime}$ O e local 2: $15^{\circ} 39^{\prime} 13.751^{\prime \prime}-47^{\circ} 51^{\prime} 19.788^{\prime \prime}$.

Foram realizadas cinco coletas de insetos, sendo a primeira do dia 06 ao dia 12 de Setembro de 2015 (inverno), a segunda do dia 13 ao dia 19 de Outubro de 2015 (primavera), a terceira do dia 18 ao dia 24 de Fevereiro de 2016 (verão), a quarta do dia 28 de Abril ao dia 04 de Maio de 2016 (outono) e a quinta do dia 07 ao dia 14 de Junho de 2016 (outono).

As armadilhas receberam numeração própria e cores nas tampas que serviram como forma de identificação. As cores vermelha, azul e amarela das tampas das armadilhas representaram respectivamente as armadilhas 1,2 e 3 .

Figura 4: Modelo de armadilha usado no experimento

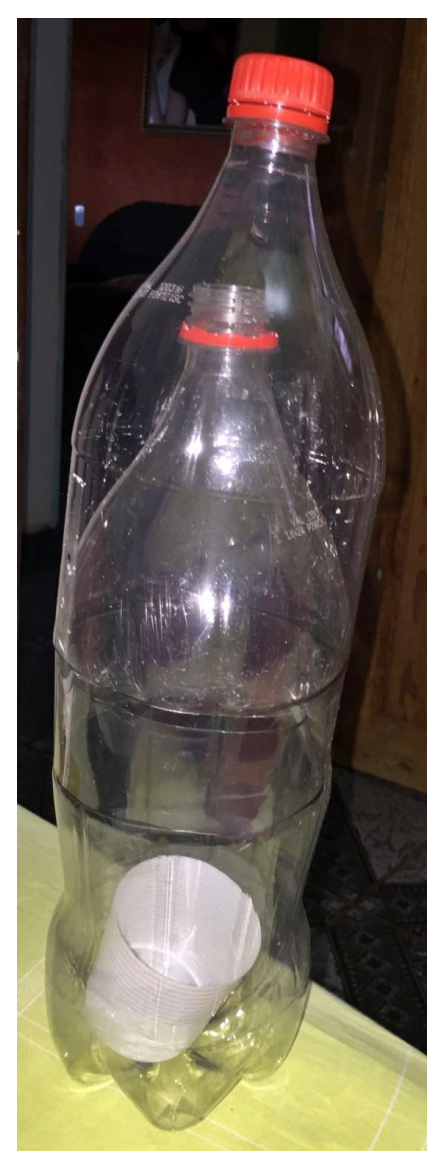

Fonte: Dos autores, 2016
Figura 5: Corte realizado no fundo da garrafa PET para permitir a entrada dos insetos

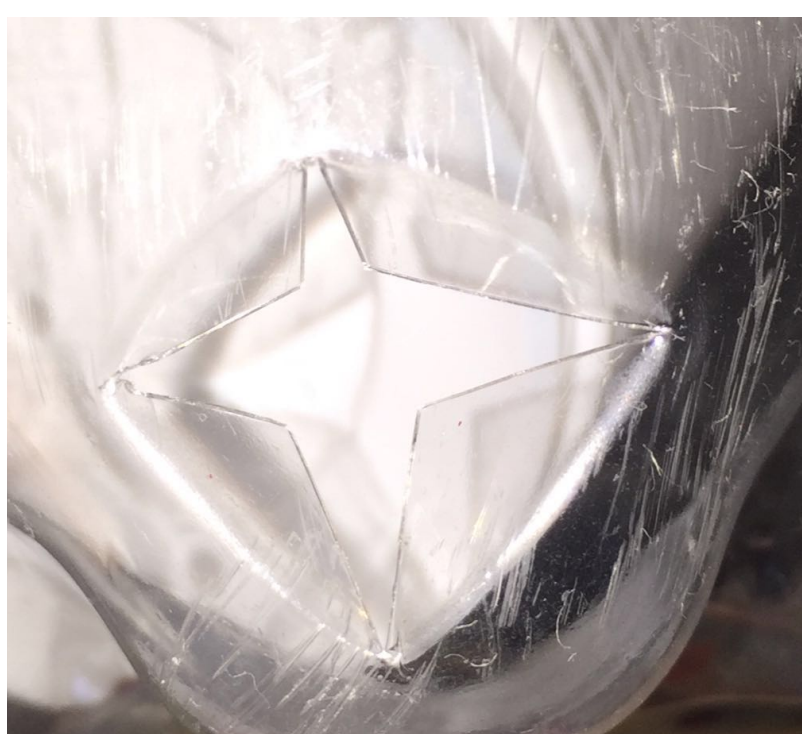

Fonte: Dos autores, 2016 


\section{RESULTADOS}

Ao final dos cinco experimentos, foram coletados 4.212 indivíduos e estes foram identificados como pertencentes às famílias Calliphoridae, Sarcophagidae e Muscidae. Foram identificados 1.562 indivíduos da família Calliphoridae. A família Muscidae foi a segunda família mais abundante, com 694 indivíduos, e a Sarcophagidae foi a terceira família mais coletada no experimento, com 172 espécimes. Além disso, os insetos pertencentes a outras famílias de dípteros corresponderam a 1.784 insetos (Tabela 1).

Tabela 1: Número total de indivíduos coletados ao longo das cinco coletas, utilizando isca de carne bovina em decomposição.

\begin{tabular}{c|c|c|c|}
\hline Familia & Local 1 & Local 2 & TOTAL \\
\hline Calliphoridae & 1178 & 384 & 1562 \\
\hline Muscidae & 280 & 414 & 694 \\
\hline Sarcophagidae & 114 & 58 & $\mathbf{1 7 2}$ \\
\hline Outros & 543 & 1241 & $\mathbf{1 7 8 4}$ \\
\hline TOTAL & $\mathbf{2 1 1 5}$ & $\mathbf{2 0 9 7}$ & $\mathbf{4 2 1 2}$ \\
\hline
\end{tabular}

A família Calliphoridae representou $37,08 \%$ dos indivíduos coletados; Muscidae, 16,47\%; Sarcophagidae, 4,08\%; e "outros" com 42,35\%.

Em seguida, para a avaliação do comportamento das famílias, utilizando-se o sistema de coleta contendo a isca, determinou-se a distribuição temporal das famílias de Diptera ao longo do período de realização do experimento (Tabelas 2, 3 e 4). 
Tabela 2: Número total de indivíduos da família Calliphoridae coletados ao longo das cinco coletas, utilizando isca de carne bovina em decomposição.

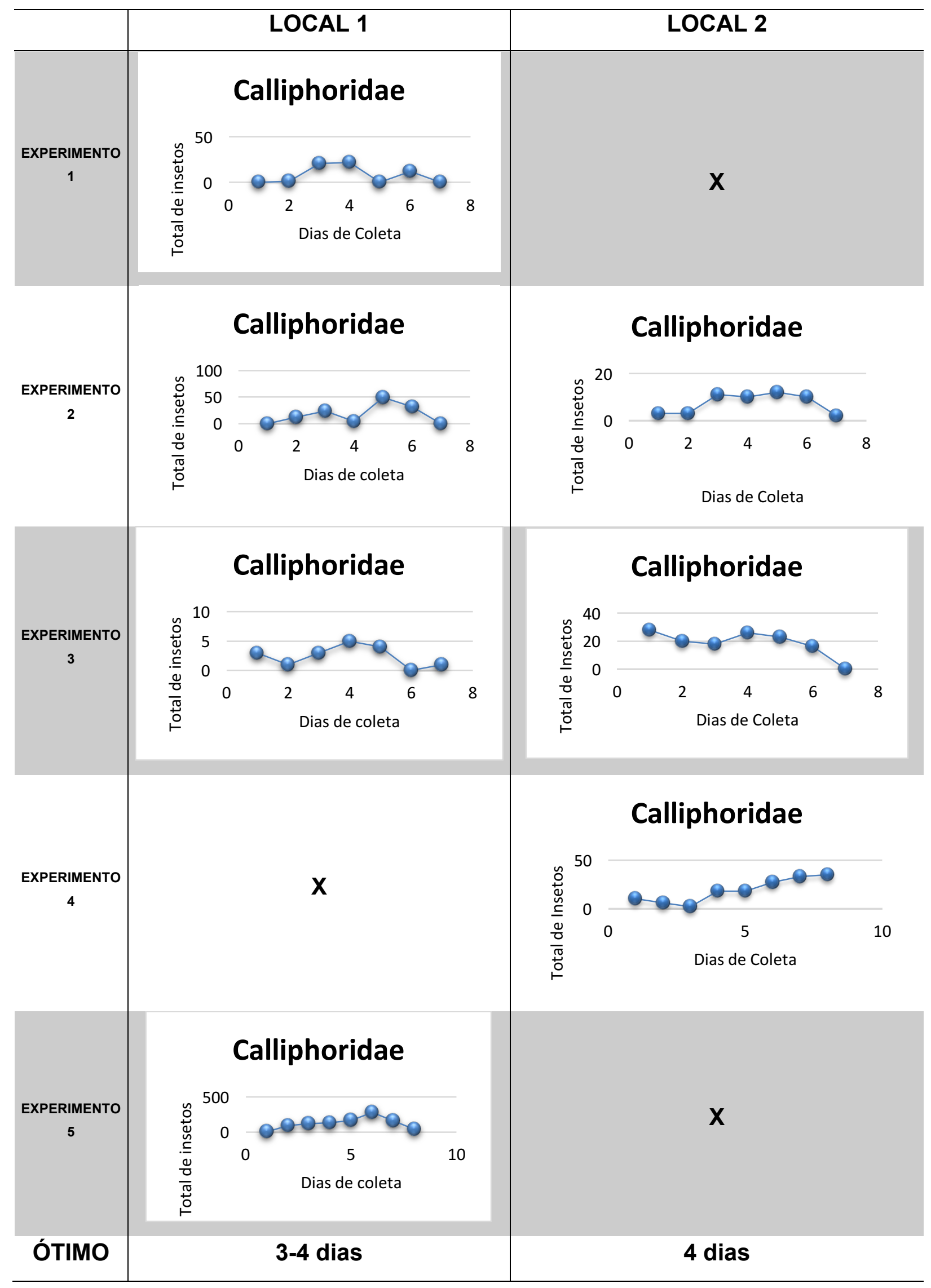


Tabela 3: Número total de indivíduos da família Muscidae coletados ao longo das cinco coletas, utilizando isca de carne bovina em decomposição.

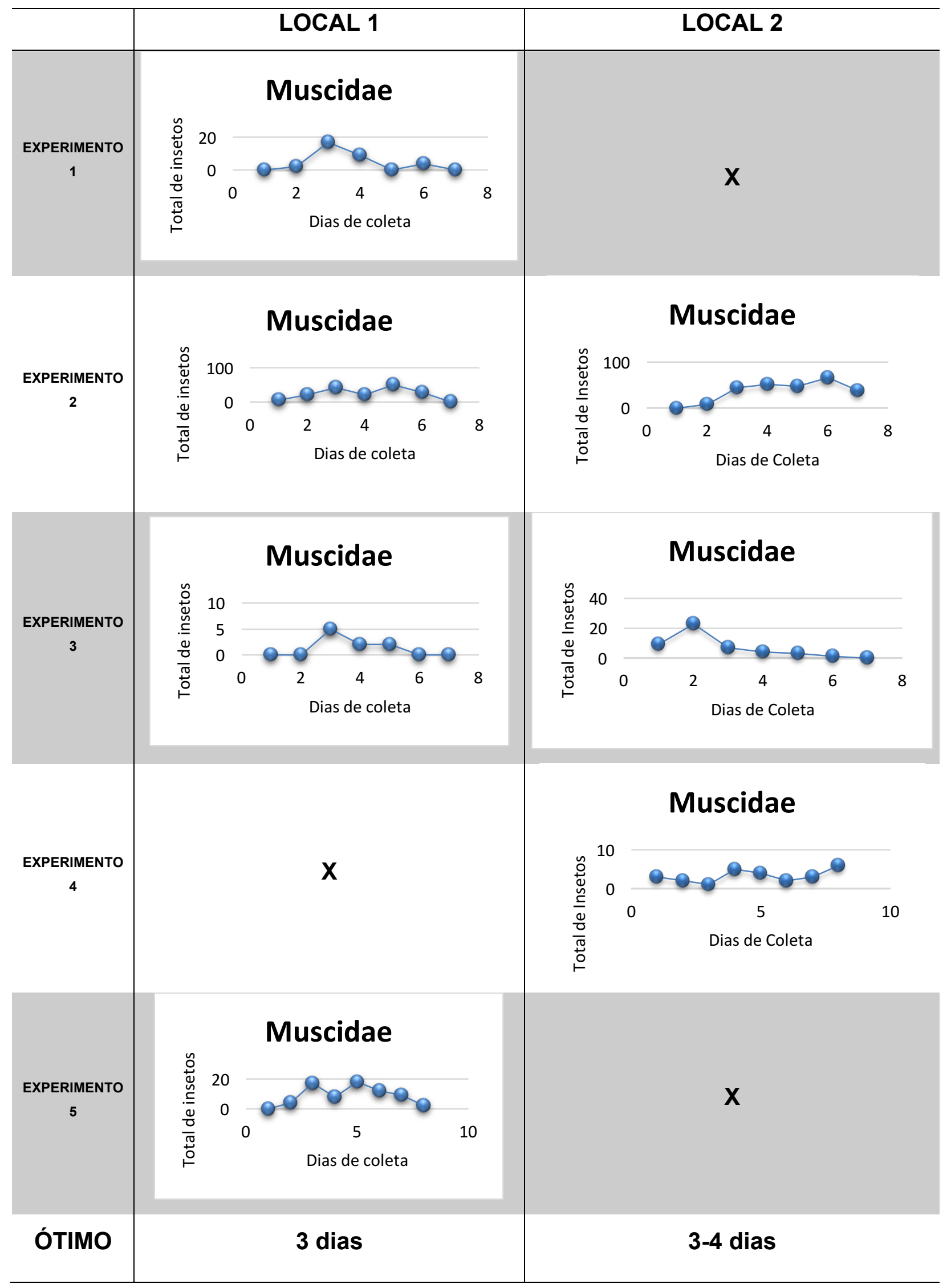


Tabela 4: Número total de indivíduos da família Sarcophagidae coletados ao longo das cinco coletas, utilizando isca de carne bovina em decomposição.

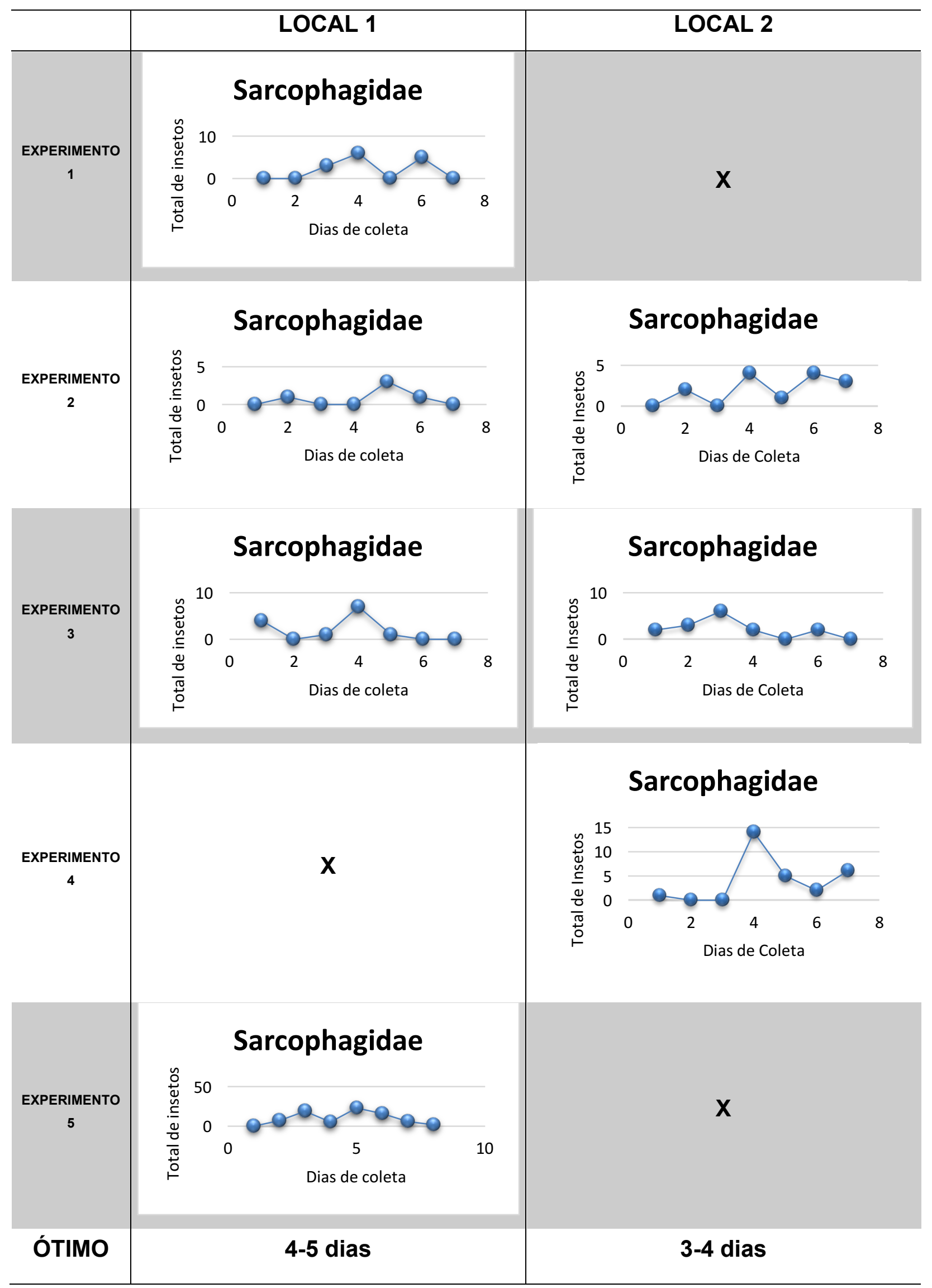


A família Calliphoridae correspondeu a maior parte das coletas, apresentando maior atividade na isca no intervalo correspondente do $2^{\circ}$ ao $7^{\circ}$ dias de decomposição. Observou-se que o pico de coleta para essa família correspondeu no intervalo entre o $3^{\circ}$ e o $4^{\circ}$ dias de experimento.

As famílias Muscidae e Sarcophagidae representaram a segunda e terceira maiores famílias de Diptera capturada. O pico de atividade dessas famílias correspondeu ao intervalo do $3^{\circ}$ ao $4^{\circ}$ dias de coleta.

A família Calliphoridae apresentou comportamento de visita à matéria orgânica em decomposição, durante todo o período de estudo.

Para Muscidae, observou-se maior frequência de visita até o $3^{\circ}$ de realização do experimento, havendo redução até o término do estudo. Sarcophagidae visitou a isca por todo o período de realização do experimento. Contudo, em termos numéricos, foi a família menos abundante nas coletas.

Para analisar possíveis variáveis que poderiam influenciar na frequência de visitas de Diptera, obtiveram-se dados de temperatura e umidade no Instituto Nacional de Meteorologia (INMET). Compararam-se, então, os dados de temperatura e umidade ao longo do intervalo de tempo de realização do experimento (Tabelas 5, 6 e 7). 
Tabela 5: Variação da temperatura e da umidade durante os dias de realização do experimento sobre a família Calliphoridae.

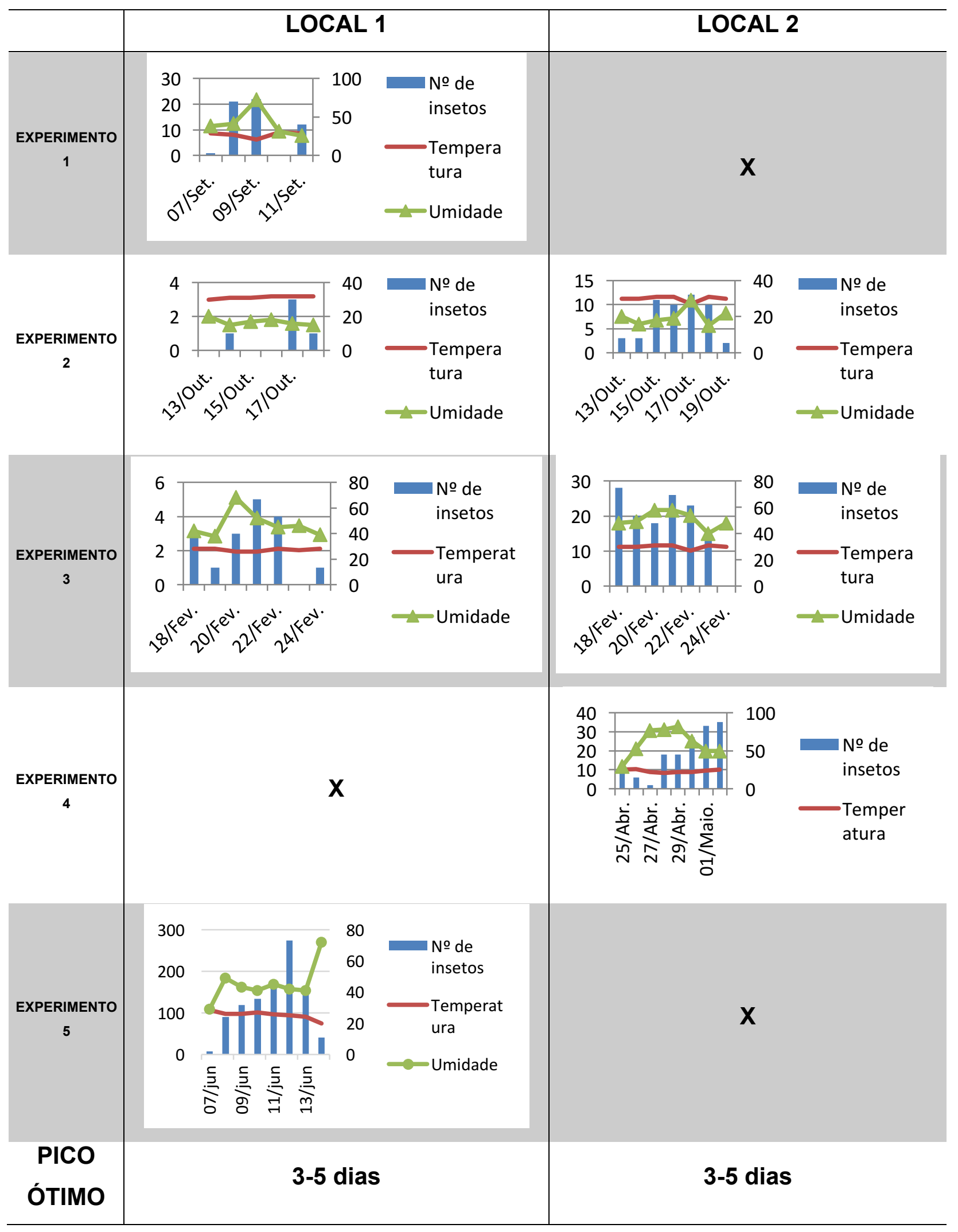


Tabela 6: Variação da temperatura e da umidade durante os dias de realização do experimento sobre a família Muscidae.

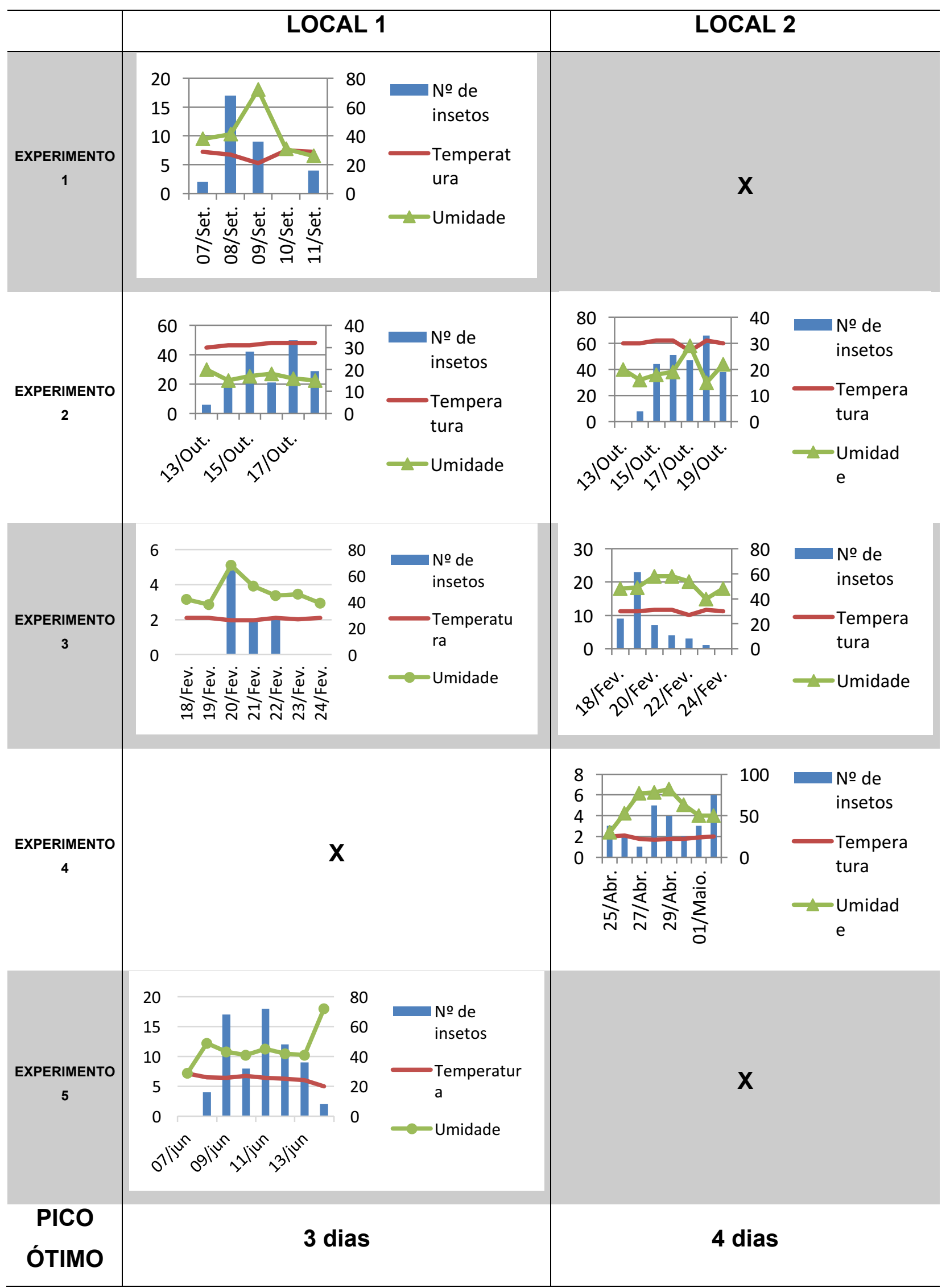


Tabela 7: Variação da temperatura e da umidade durante os dias de realização do experimento sobre a família Sarcophagidae.

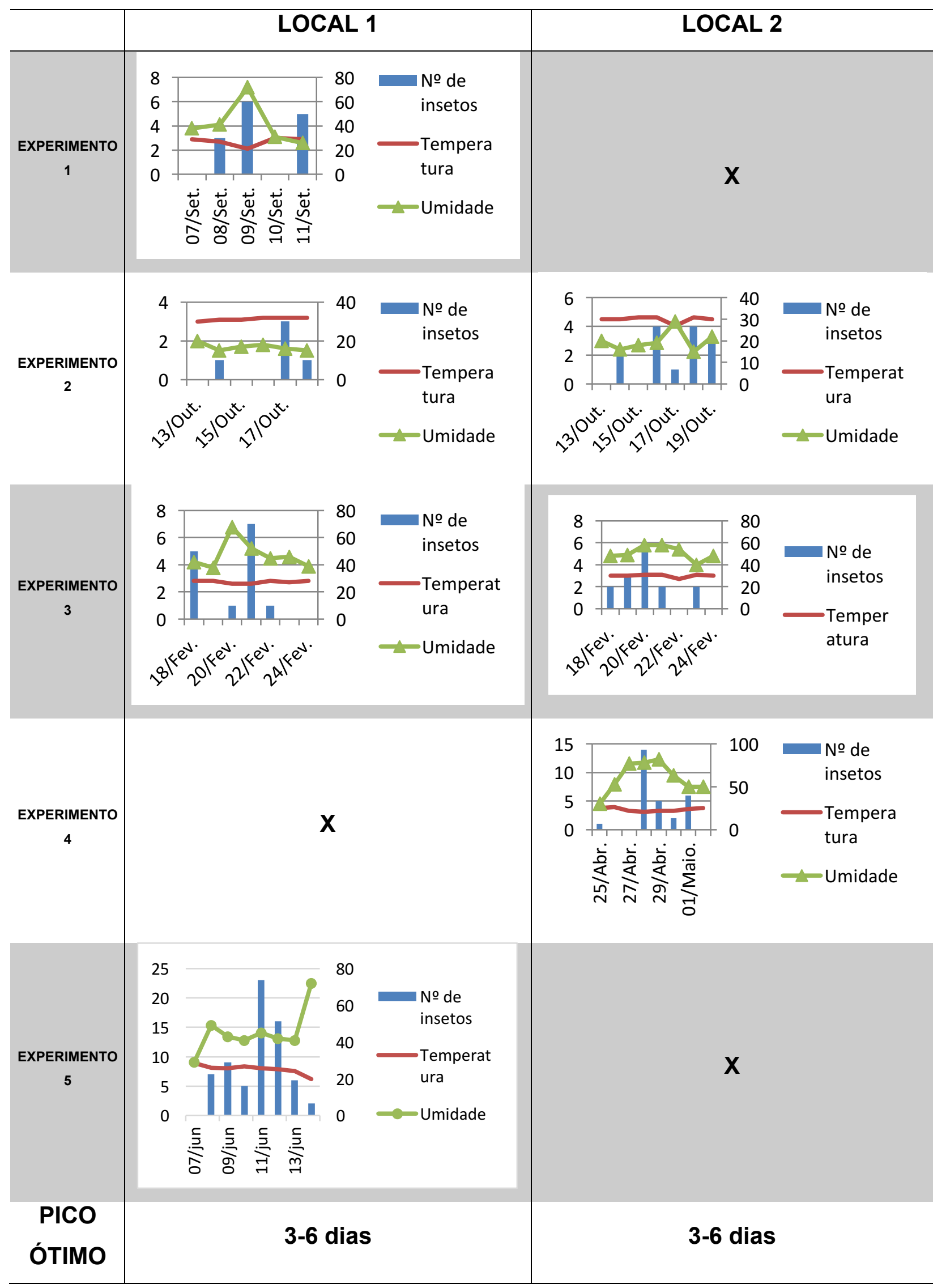


A temperatura e a umidade exerceram influência sobre o comportamento dos insetos, uma vez que, houve relação entre alguns dos picos de coleta de cada família e as variações de temperatura, mas principalmente de umidade. Por meio da análise dos gráficos, foi possível observar que as coletas mantiveram-se contínuas, apresentando um nível de coleta maior ou menor de uma espécie relacionada com a fase de decomposição em que se encontrava a isca. As maiores influências no experimento foram a localização das armadilhas, o tipo de carne utilizado como isca e a incidência ou não de chuva, uma vez que, quando ocorria chuva, o número de indivíduos coletados era baixo.

Os dados obtidos das capturas possibilitaram observar a influência dos estágios de decomposição da isca na frequência de coleta dos indivíduos de três famílias de Diptera (Tabelas 2, 3 e 4). Observou-se mudança de cor da isca, indo do vermelho ao verde, atingindo a cor enegrecida. Além disso, durante a evolução da fase cromática, observou-se a liberação substâncias odoríferas associadas à decomposição da carne, bem como, o inchaço associado à produção de gases pela ação microbiana.

A cada etapa do processo de decomposição da isca, observou-se atratividade diferenciada de insetos com maior atividade nos períodos de liberação de odor da isca, reduzindo-se à medida que a isca atingia a cor enegrecida.

\section{DISCUSSÃO}

Diversos trabalhos sobre entomologia forense descrevem a grande quantidade das famílias de Diptera que possuem a capacidade de se desenvolverem sobre uma matéria orgânica que esteja em processo de decomposição como no caso das espécies das famílias Calliphoridae, Muscidae e Sarcophagidae, que foram identificadas nas três armadilhas que foram colocadas em períodos estacionais diferentes. No entanto, também foram identificadas outras espécies durante 0 período de decomposição da carne bovina, mostrando assim a grande variedade de insetos que possuem a capacidade de utilizar esse material como uma fonte alternativa de nutrição (DOREA et al., 2006).

A armadilha que foi usada nesse trabalho possui um sistema de câmeras a qual facilita a entrada, porém dificulta sua saída. Assim, os insetos tentam alçar voo para cima, mas permanecem presos até a hora de sua coleta. Ela também acabou 
sendo um objeto de grande utilidade, pois era de montagem simples e com material completamente descartável e de baixo custo.

Com base nas análises forenses, as famílias Sarcophagidae e Calliphoridae se mostraram muito mais informativos, já que são os dípteros que acabam colonizando o corpo em primeiro lugar e levam ao surgimento de uma sucessão de espécies de acordo com o avanço da decomposição do material orgânico. Contudo, o ciclo de vida dos Sarcophagidae é diferente dos Calliphoridae, pois eles depositam suas larvas no seu primeiro estádio obtendo, como consequência, um desenvolvimento mais lento dentro no interior da fêmea fazendo assim com que sua reprodução seja menor quando comparada as das famílias Calliphoridae e Muscidae (SILVA; QUEIROZ, 2016).

Nesse estudo, as famílias de Diptera foram analisadas através de uma planilha onde apresentaram um acumulo de taxas em dias distintos, levando a formação de uma curva com inclinações bem características. Essa simulação possibilitou na identificação de um possível padrão de recrutamento para essas três famílias.

A partir do sistema de simulação que foi elaborado, foi possível estabelecer um padrão de recrutamento para três famílias de Diptera. Esse padrão poderá ser expandido para trabalhos em campo utilizando-se carcaças de animais para confirmação desse processo.

\section{CONSIDERAÇÕES}

O presente estudo levou a uma coleta de dados dos quais possibilitaram no estabelecimento de modelos logísticos, usando um sistema de simulação com a utilização de uma carne bovina em decomposição, para a coleta de três famílias de Diptera.

Os insetos identificados da família Sarcophagidae foram contados com uma taxa muito inferior quando comparado aos indivíduos das famílias Calliphoridae e Muscidae mostrando assim uma diferença no padrão de recrutamento da primeira família em relação as outras duas. 
Os dados de coleta permitiram estabelecer modelos logísticos para o recrutamento de três famílias de Diptera utilizando um sistema de simulação, contendo carne em decomposição como isca.

Os indivíduos pertencentes às famílias Calliphoridae e Muscidae apresentam o mesmo padrão de recrutamento, enquanto Sarcophagidae apresentou um padrão de recrutamento diferente dos demais.

\section{REFERENCIAS BIBLIOGRÁFICAS}

BIOSURVEY. Flesh Fly, 2004. Disponível em: <http://www.biosurvey.ou.edu/okwild/ misc/fleshfly.html> acessado em: 20/08/2016

BRASIL. Ministério da Justiça. Coleta de amostras de insetos para fins Forenses. Brasília. Ago. 2006.

CAINÉ L.S.R.M. Entomologia Forense: Identificação Genética de Espécies em Portugal. Dissertação em Ciências da Saúde, Faculdade de Medicina da Universidade de Coimbra, 2010.

DIPTERA.INFO. Disponível em: <http://diptera.info/forum/viewthread.php?thread_id= 41988\&pid=184150> Acessado em: 20/08/2016

DOREA, L. E. C. et al. Criminalística. 3. ed.Campinas: Millennium, 2006.

GOMES, L. Entomologia Forense: Novas tendências e tecnologias nas ciências criminais. Rio de Janeiro. Ed. Technical Books, 2010.

GUIMARÃES, R. R.; GUIMARÃES, R. R. Armadilhas usadas para coleta de dípteros muscóides (Insecta: Diptera). Boletin Sociedad Entomológica Aragonesa, Madrid, n. 33, p. 281- 283, Oct. 2003.

GUPTA, A.; SETIA, P. Forensic entomology-past, present and future. Aggrawal's Internet Journal of Forensic Medicine and toxicology, Nova Delhi, v.5, n.1, p.50$53,2004$.

LUZ et al. Cem anos da Entomologia Forense no Brasil (1908-2008). Revista Brasileira de Entomologia. v.52, n 4, p. 485-492. Dez. 2008.

MARTINS G. et al. Estimativa do intervalo pós-morte em um canino (Canis lúpus familiaris linnaeus 1758) pela entomologia forense em Cabedelo-PB, Brasil: relato de caso. 2013. Disponivel em: $<$ http://www.scielo.br/scielo.php?script=sci arttext\&pid=S0102-09352013000400024 \&lang=pt>

OLIVEIRA-COSTA, J. Entomologia Forense: Quando os insetos são vestígios. São Paulo: Editora Millenium, p. 420, 2008. 
PINHEIRO et al. Variáveis na estimativa do intervalo pós-morte por métodos de Entomologia Forense. Enciclopédia Biosfera. Goiânia. v.8, n 14, p.1442. Jun. 2012.

PINTO K.V. et al. Pictorial identification key for species of Sarcophagidae (Diptera) of potential forensic importance in southern Brazil. V. 55, n. 3. São Paulo, SP. 2011. Disponível em: <http://www.scielo.br/scielo.php?script=sci arttext\&pid=S0085-56262011000300006\&lang = pt>

RAMOS L.S. Entomologia Forense, identificação genética de espécies em Portugal. PT,2010. Disponível em: <https://estudogeral.sib.uc.pt/bitstream/10316/ 14540/3/Tese\%20doutoramento Laura\%20Cain\%C3\%A9.pdf>

ROMANA A. et al. A importância da Entomologia forense nas investigações criminais. Tocantins, 2012. Disponível em: <http://propi.ifto.edu.br/ocs/index. php/connepi/vii/paper/view File/1879/1552>

SANTANA C.S, BOAS D.S.V. Entomologia Forense: Insetos Auxiliando a Lei. Revista Ceciliana. São Paulo. v.4, n.2, p. 31-34. Dez. 2012

SILVA T.N; QUEIROZ P.R.M. Características da família Sarcophagidae aplicadas á análise forense. Disponível em: <http://www.cpgls.pucgoias.edu.br/6mostra/artigos/ SAUDE/THARA\%20NUNES\%20SILVA\%20E\%20PAULO\%20ROBERTO\%20QUEIR OZ.pdf > acesso em 14/08/2016. 